\title{
ASSESSMENT OF THE HEALTH RISKS OF THE EXPOSURE TO ORGANOPHOSPHATE AMONG MALES
}

\author{
Albokhary, M. S. ${ }^{(1)}$; Radwan, O. M. ${ }^{(1)}$; Awad Allah, Hala, I. $^{(1)}$; \\ Sallam, Nancy, M. $^{(1)}$ and Sultan, Eman, A. ${ }^{(2)}$ \\ 1) Institute of Environmental Studies and Research, Ain Shams University \\ 2) Department of Clinical Nutrition, National Nutrition Institute
}

\begin{abstract}
Over the past 20 years, a great deal of attention has focused on the impact of endocrine disruptors released in the environment on animal and human health. Generally, endocrine disruptors have estrogenic activity. These products interfere with hormone biosynthesis, metabolism, or action resulting in a deviation from normal homeostatic control or reproduction. Our primary objective was to evaluate the possible role of environmental estrogen on sexual disturbance among males.

Methods: A cross-sectional study recruited 26 apparently healthy males characteristics of life style, symptoms covering various systems, general examination including, body mass index, waist line, resting blood pressure were done. Venous blood samples were used for detection of both total testosterone \& plasma (Butyryl choline esterase (BuChE) activity.

Results: the mean age was $(36.54 \pm 6.04)$ years with mean BMI of $(28.98 \pm$ $5.16) \mathrm{kg} / \mathrm{m} 2$. , mean waist $(102.78 \pm 11.18) \mathrm{cm}$. $66.7 \%$ of the cases were married with $13.3 \%$ of them have fertility problem \& $20 \%$ of sample have sexual problem. $66.7 \%$ of the studied group use pesticide at home. The main findings of this study were, regarding hormonal profile; nearly all studied group had hormonal values and acetylecholine esterase (AChE) within the reference range but there is a negative association between organophosphate (OP) pesticides exposure assessed by the AchE as indicator and serum total testosterone levels. AchE was also negatively associated with fruit \& vegetables consumption/week; whereas there is a positive association with age.
\end{abstract}

Key words: Organophosphate, xenoestrogen, Acetyle choline esterase (AChE),male hormones, total testosterone . 
J. Environ. Sci.

Institute of Environmental Studies and Research - Ain Shams University

\section{INTRODUCTION}

A major challenge for life scientists in the 21 st century is to understand how a changing environment impacts all life on earth. Exposure to environmental chemicals which have major risks for human by targeting different organs in the body has significant impacts on biological systems. For several years there have been a great amount of interest on the environmental endocrine disruptors (EEDs) and their relation with human health (Li et al., 2016).

Endocrine-disrupting compounds (EDCs) are synthetic and naturally occurring chemicals that may interfere with endogenous endocrine action;

Exposure to EDCs has been associated with reproductive problems, obesity, diabetes, cancers, and behavioral and learning disorders (WHO/UNEP 2013).Several substances are thought to cause endocrine disruption; most EDCs are classified as xenoestrogens whereas others inhibit androgen production and function (Meeker, 2012).

The potential for deleterious effects of EDC must be considered relative to the regulation of hormone synthesis, secretion, and actions and the variability in regulation of these events across the life cycle. Because endocrine systems exhibit tissue-, cell-, and receptor-specific actions during the life cycle, EDC can produce complex, mosaic effects. This complexity causes difficulty when a static approach to toxicity through endocrine mechanisms driven by rigid guidelines is used to identify EDC and manage risk to human and wildlife populations (Zoeller et al., 2012). 
The mechanisms of EDCs involve divergent pathways among them including (but not limited to) estrogenic, antiandrogenic, steroidogenic enzymes; neurotransmitter receptors and systems; and many other pathways that are highly conserved in wildlife and humans (Diamanti-Kandarakis et al., 2009).

One class of EDCs is the environmental pesticides that broadly classified in to organophosphorus (OPs), organochlorine, carbamates (CBs) and pyrethroids (Haque et al., 2012).OPs are one of the most widely used classes of pesticides that being employed for both agricultural and landscape pest control. The use of OP has increased considerably due to their low toxicity and low persistence in the mammalian system compared to organochlorine pesticides (Kamath\&Rajini, 2007). Due to the similarity with human physiological function, these chemicals can harm normal human body (Makelarski et al., 2014).OP pesticides are esters of phosphoric or thiophosphoric acid, whose toxicity has been related to their ability to inhibit acetylcholinesterase activity causing acetylcholine accumulation at the nerve synapse level (Ecobichon \& Klaassen 2001) and this enzyme, has been used the most in enzymatic detection of these pesticides.

Because of existing concerns about the anti-androgenic activity of environmental OPs, we evaluated the possible role of environmental estrogen on sexual disturbance among males.

Aim of the Work: To evaluate the association between environmental exposure to organophosphate (OP) measured by AchE and evaluating its possible role on sexual disturbance among males. 
Methods: A cross-sectional study that recruited 26 apparently healthy males that agreed to participate in the study after explained details about the study and investigation that will be done and signed the informed consent for the study.

\section{Inclusion Criteria:}

- Apparently healthy males aged from 20-45 years.

-Ability to provide written informed consent.

-Able to comply with the procedures of the study protocol.

\section{Exclusion Criteria:}

-Has been diagnosed with diabetes or endocrinal problems such as hypogonadism, pituitary problems, hypothalamic or thyroid problems.

- Poorly controlled hypertension.

-Subjects with major illness such as cancer, hepatic, psychiatric or cardiac diseases.

Methods: This study carried on apparently healthy males from relatives and males attending courses in national nutrition institute from 12/2016 till 2/2017.

1-Medical Assessments including family history of chronic noncommunicable diseases, symptoms covering various systems, general examination including blood pressure measurements, pulse, chest, heart and abdominal examination.

a. Anthropometric Measurements: Weight and height: Body weight was measured with scale to the nearest $0.1 \mathrm{~kg}$, with the subject wearing only light clothing. Height was measured to the nearest $0.5 \mathrm{~cm}$ with the subject 
standing on the floor without shoes with the back straight against the wall (Jelliffe \& Jelliffe, 1989). BMI was calculated as the ratio of the weight and height squared $(\mathrm{kg} / \mathrm{m} 2)$ and assessment of BMI was done using categories reported by (WHO, 1995).

Waist circumference: Waist was measured with the subject in standing position at the top of the iliac crest to the nearest $0.5 \mathrm{~cm}$ (NHLBI Obesity Education Initiative, 2000) and hip circumference was measured as the maximum circumference over the buttocks to the nearest $0.5 \mathrm{~cm}$ (WHO,2008).

B-Biochemical Measurements:Venous blood samples were drown into heparinized tubes and plasma was separated by centrifugation of blood samples at $3000 \mathrm{rfm}$ for 10 minutes.

- Plasma BuChE activity was measuredwith a Test-mate ChE Randox kit from the hydrolysis of butyrylcholine iodide, and data were expressed as micromoles per minute per milliliter of plasma (U/ml). Evaluation of Testmate $\mathrm{ChE}$ results was based on $\mathrm{AChE}$ and $\mathrm{BuChE}$ inhibition associated with different degrees.

- Quantitative determination of Testosterone $(\mathrm{ng} / \mathrm{ml})$ in human serum byenzyme immunoassay using commercially available kit DRG® Testosterone ELISA (EIA-1559), the DRG® testosterone ELISA Kit is a solid phase enzyme-linked immunosorbent assay (ELISA), based on the principle of competitive binding normal range (3-11 ng/ml) (Tietz, 1986) . Statistical Analysis: Number and percent (\%) for categorized or numerical data. Statistical analysis Continuous variables were expressed as means + SD. To establish differences between continuous variables, The Student's $t$ test 
was applied to detect differences between the means of two normally distributed populations. The degree of association between variables was evaluated based on Pearson's or Spearman's correlation coefficient. Statistical analysis was performed with Statistical Package for the Social Sciences (SPSS) (Version 13.2, 2003, Echosoft Corp., USA).A level of $(\mathrm{P}<0.05)$ was accepted as statistically significant, and a level of $(\mathrm{P}<0.001)$ was accepted as statistically highly significant.

\section{RESULTS}

Table (1) \& (2) present the general characteristics of the study population, the mean age was $(36.54 \pm 6.04)$ years with mean BMI of $(28.98$ $\pm 5.16) \mathrm{kg} / \mathrm{m}^{2}$, mean waist $(102.78 \pm 11.18) \mathrm{cm} .66 .7 \%$ of the cases were married and $13.3 \%$ of those married have fertility problem \& $20 \%$ with sexual problem. $66.7 \%$ of the studied group use pesticide at home. The mean serving intake of fruit \& vegetables /week were (2.65 \pm 2.90$)$ serving. Regarding hormonal profile, nearly all studied group had total testerone \& AchE values within the reference range with mean of $(11.54 \pm 2.62) \&$ $(8847.58 \pm 1908.13)(\mathrm{U} / \mathrm{ml})$ respectively. When correlated AchE levels with other variables there was a significant positive correlation with age $(\mathrm{P}=$ $\left.0.008^{* *}\right)$ but, a significant inverse correlation with total testosterone fig (1) with $\left(\mathrm{P}=0.010^{*}\right) \&$ with fruit $\&$ vegetables consumption/week $\left(\mathrm{P}=0.024^{*}\right)$ table (3). 
Table (1): Characteristics of the study population

\begin{tabular}{|c|c|}
\hline Variable & Mean \pm SD \\
\hline Age/years & $36.54 \pm 6.04$ \\
\hline Weight/kg & $86.17 \pm 15.12$ \\
\hline Height/cm & $172.57 \pm 6.15$ \\
\hline BMI kg/m2 & $28.98 \pm 5.16$ \\
\hline Waist/ cm & $102.78 \pm 11.18$ \\
\hline Hip/cm & $106.53 \pm 8.44$ \\
\hline Waist /Hip Ratio & $0.94 \pm 0.05$ \\
\hline Systolic blood pressure/mmHg & $133.00 \pm 12.84$ \\
\hline Diastolic blood pressure/mmHg & $84.70 \pm 9.58$ \\
\hline Fruit \& vegetables consumption/week & $2.65 \pm 2.90$ \\
\hline Hemoglobin(gm/dl) & $13.86 \pm 1.03$ \\
\hline Random blood glucose $(\mathrm{mg} / \mathrm{dl})$ & $90.0 \pm 14.31$ \\
\hline Acetylcholine esterase $(\mathrm{U} / \mathrm{ml})$ & $8847.58 \pm 1908.13$ \\
\hline Total testosterone(ng/ml $)$ & $11.54 \pm 2.62$ \\
\hline
\end{tabular}

Table (2): Characteristics of the study population

\begin{tabular}{|c|c|c|}
\hline Variable & & \% \\
\hline \hline Married & & 66.7 \\
\hline Fertility problem & & 13.3 \\
\hline \multirow{4}{*}{ Number of Shaving/months } & 1 & 4.2 \\
\cline { 2 - 3 } & 3 & 12.5 \\
\cline { 2 - 3 } & 4 & 16.7 \\
\cline { 2 - 3 } & 5 & 20.8 \\
\cline { 2 - 3 } & 11 & 45.8 \\
\hline Week Muscle power & & 9.1 \\
\hline Sexual problems & & 20.0 \\
\hline Use of pesticide & & 66.7 \\
\hline \multirow{3}{*}{ Fruit \& vegetable consumption } & 0.5 & 8.7 \\
\cline { 2 - 3 } /week & 1.0 & 30.4 \\
\cline { 2 - 3 } & 2.0 & 30.4 \\
\cline { 2 - 3 } & 3.0 & 8.7 \\
\cline { 2 - 3 } & 4.0 & 13.0 \\
\cline { 2 - 3 } & 7.0 & 4.3 \\
\cline { 2 - 3 } & 14.0 & 4.3 \\
\hline \hline
\end{tabular}


J. Environ. Sci.

Institute of Environmental Studies and Research - Ain Shams University

Table (3): Correlations between AchE and other variables

\begin{tabular}{||l|c|c|}
\hline \multicolumn{1}{|c|}{ Variable } & r & P \\
\hline Age/years & $0.576^{* *}$ & $0.008^{* *}$ \\
\hline Weight/kg & 0.332 & 0.165 \\
\hline Height/cm & $-0.326-$ & 0.173 \\
\hline BMI kg/m2 & 0.423 & 0.071 \\
\hline Waist/ cm & 0.359 & 0.131 \\
\hline Hip/cm & 0.375 & 0.152 \\
\hline Waist /Hip Ratio & 0.037 & 0.892 \\
\hline Systolic blood pressure/mmHg & 0.319 & 0.182 \\
\hline Diastolic blood pressure/mmHg & 0.229 & 0.345 \\
\hline Hemoglobin/gm/dl & -0.020 & 0.933 \\
\hline Random blood glucose (mg/dl) & 0.101 & 0.672 \\
\hline Total testosterone(ng/ml) & $-0.638^{*}$ & $0.010^{*}$ \\
\hline Number of shaving/month & -0.058 & 0.813 \\
\hline Fruit \& vegetables consumption/week & $-0.514^{*}$ & $0.024^{*}$ \\
\hline
\end{tabular}

${ }^{\times} \mathrm{A}$ level of $(\mathrm{P}<0.05)$ was accepted as statistically significant,

${ }^{\times x} \mathrm{~A}$ level of $(\mathrm{P}<0.001)$ was accepted as statistically highly significant ${ }^{\times}$ 


\section{DISCUSSION}

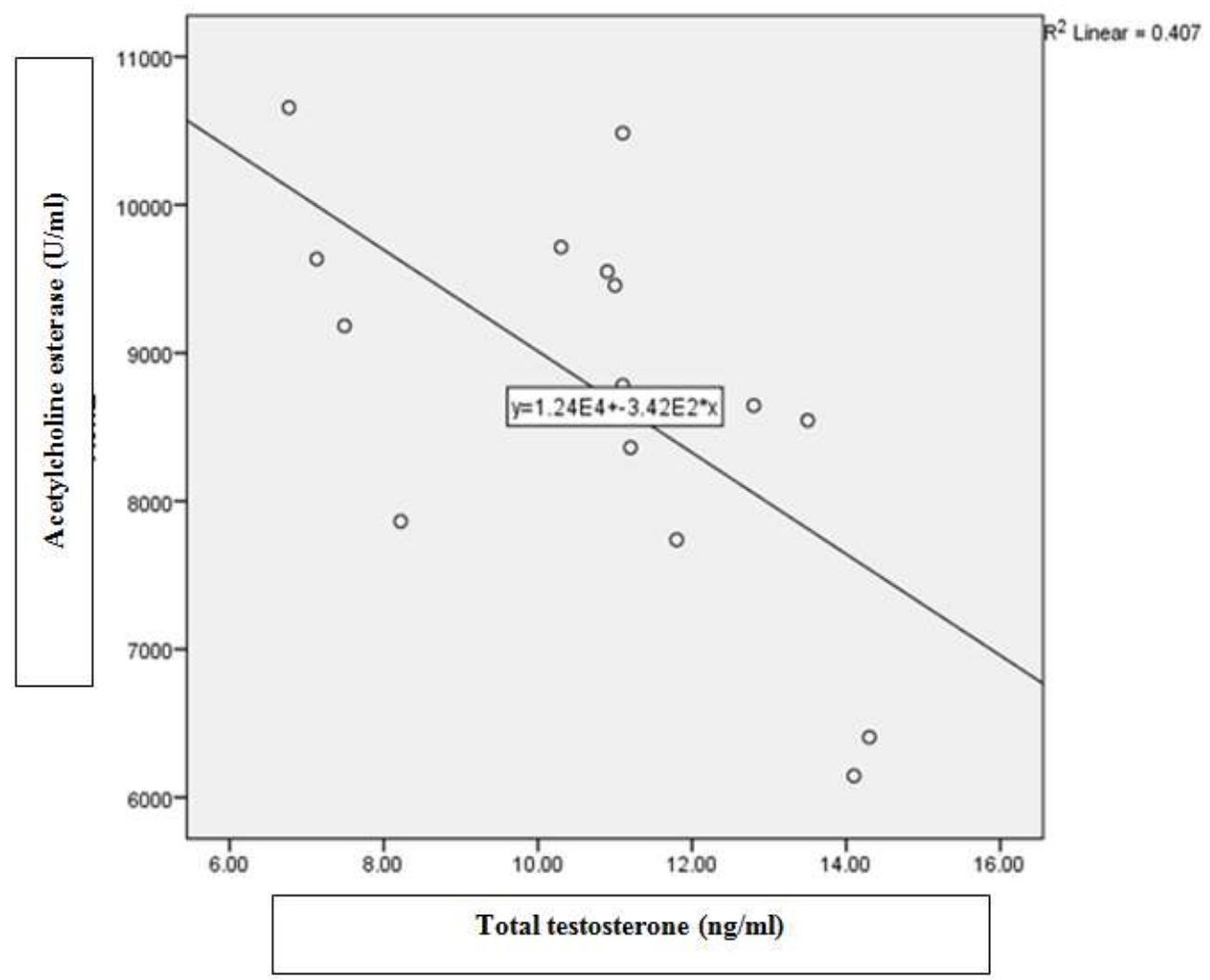

Figure (1): Correlation between testosterone and AchE

There is substantial toxicological evidence that repeated low-level exposure to organophosphate (OP) pesticides may have potential adverse health effects (Eskenazi et al., 1999). In the past years, there has been increased interest in assessing the relationship between impaired male fertility and environmental factors. Human male fertility is a complex process and therefore a great variety of sites may be affected by exogenous harmful mediators. Lifestyle factors as well as various environmental and 
occupational agents may impair male fertility. Many studies have been published reporting on reproductive dysfunctions in male animals and humans (Pflieger-Bruss et al., 2004). However, relevant epidemiology studies in men are limited.

In our study nearly all studied group had total testerone values and AChE within the reference range but there is a negative association between OP pesticides exposure assessed by the AchE as indicator and serum total testosterone levels. The same reported by, Straube et al. (1999), who showed that testosterone levels decrease during acute exposure whereas its levels are increased during chronic exposure. These findings are also consistent with studies on rats, in which subchronic exposure associated with an increase in serum testosterone (Sarkar et al., 2000), another study that evaluated the effect of exposure to organophosphate pesticides on male hormone profile showed that most hormonal values fell within the wide normal range and recommends the need for further investigation to elucidate their biological and clinical relevance (Blanco-Munoz et al., 2010). But Soliman et al (2008) \& Arafa et al., (2013) in their studies among Egyptians farmers\& workers showed that chronic exposure to organophosphate can cause endocrine disrupting effects with low testerone in exposed group. On the other hand, Kamijima et al (2004) found a significantly increased concentration than normal of serum testosterone concentrations after organo- phosphorous exposure during the off-season 
Altered serum reproductive hormone levels have also been reported in epidemiology studies of OP insecticide exposure conducted in men (Meeker et al., 2008), for example, serum testosterone levels were inversely related to urinary biomarkers of OP insecticide exposure in cohorts of men from a U.S. fertility clinic (Meeker et al., 2006).

In a recent study evaluated urinary concentrations of OP in relation to serum concentrations of testosterone among 356 men aged 20-55 years old from the U.S. National Health and Nutrition Examination Survey. Biomarkers were detected in greater than $50 \%$ of the samples. In adjusted regression models, they observed a statistically significant inverse relationship between OP and total serum testosterone levels (Omoike et al., 2015) .Studies conducted in rodent species have also demonstrated decreases in $\mathrm{T}$ following exposure to the OP. This analysis represents a unique contribution to the state-of-the-science on the potential link between exposure to OP insecticides and male reproductive hormones (Aguilar-Garduño et al., 2013).These findings add to the limited evidence that exposure to certain OP insecticides is linked to altered $\mathrm{T}$ in men, which may have important implications for male health (Omoike et al., 2015).

There is a growing concern about the endocrine effects of long-term, low-level exposure to organophosphate (OP) compounds. Studies on experimental animals have found that OP pesticides have an impact on the endocrine system and a few clinical and epidemiological studies have also shown that OPs may affect the male hormone profile, although results are inconsistent. OP pesticides may have an impact on the endocrine function because of their potential to modify the male hormone profile as a function of 
the type of pesticide used as well as the magnitude of exposure (AguilarGarduño et al., 2013).

Although many studies suggest the need to put into effect regulations regarding the proper use of pesticides on vegetables due to the high levels and wide assortment of pesticide residues found in vegetables (Armah, 2011) \& (Akan et al., 2013).

As the primary route of exposure to OPs is via ingestion of contaminated food (Lu et al., 2008); in contrast to our expectation, AchE was also negatively associated with fruit $\&$ vegetables consumption/week.

In a study evaluating the pesticide residues in some Egyptian fruits, the most detected pesticide groups were Pyrethroids, $27.8 \%$ followed by Organophosphates (OP's) 24.6\%, On the other hand, OP's are the most

violated group. Data showed that pesticides which not recommended for using in tested fruits were detected in frequency of $76.1 \%$ of the findings as well as pesticides revoked by Egyptian authorization (Gad Alla et al., 2015).

In a study on the pesticide residues in food from Egyptian local market none of the detected organophosphorus pesticides found in citrus fruits exceeded their maximum residue level (MRL) (Dogheim et al., 1996).

Available evidence suggest that there is a possibility of adverse effects occurring below OP compounds concentrations that are generally considered to be safe based on measurement of AChE inhibition (Singh \& Sharma, 2000 and Salvi et al., 2003).Delayed effects of pesticide are illnesses or injuries that do not appear immediately (within 24 hours) after exposure to a pesticide. Adverse effects may be delayed for weeks, months or compound, 
dosage and exposure time (Jors et al., 2006) and the health effects of low dose pesticides exposure are very difficult to evaluate mostly when pesticides mixtures are used (Lewalter \&Leng, 1999 and Carpy et al., 2000).

Although we did not directly assess consumption of food, organically grown foods have been reported to have significantly lower pesticide residues than conventionally grown foods (Baker et al., 2002; Lu et al., 2006). A study conducted among the members of a Danish association of organic farmers reported that sperm concentration was $43.1 \%$ higher among men eating organically produced food (Jensen et al., 1996).

There is substantial evidence that dietary antioxidant supplementation and/or increased ingestion of fruit and vegetable may play a role in neutralizing or buffering the effects of pollutants. In vitro and in vivo studies suggest that antioxidant nutrients and related bioactive compounds common in fruits and vegetables can protect against environmental toxic insults (Poljšak \&Fink, 2014). A study carried out by Zheng et al., 2015 shown that fruit-vegetable dietary pattern may reverse oxidative stress and even genetic damage. The key mechanism of pesticides' cytotoxicity may be linked to their pro-oxidative potential, including damage by free radical oxidation of cellular components such as membrane lipids, protein and DNA and antioxidants may attenuate the pesticides-induced cell toxicity (Ilboudoa et al. 2014; Poljšak and Fink 2014).However, because our assessment of pesticide based on AChE, rather than on direct measurement of pesticides, further confirmation of these findings is warranted. Thus, we are unable to test the role that this potential bias may play in our findings. 


\section{REFERENCES}

Aguilar-Garduño C, Lacasaña M, Blanco-Muñoz J, Rodríguez-Barranco M, Hernández AF, Bassol S, González-Alzaga B and Cebrián ME (2013): Changes in male hormone profile after occupational organophosphate exposure. A longitudinal study. Toxicology.10: 307, 55-65.

Akan, J.C., Jafiya, L., Mohammed, Z. and Abdulrahman, F.I., (2013): Organophosphorus pesticide residues in vegetables and soil samples from Alau Dam and Gongulong agricultural areas, Borno State, Nigeria. Ecosystems, 3, p.6.

Arafa A, Afify M and Samy Nervana (2013): Evaluation of Adverse Health Effects of Pesticides Exposure [Biochemical \& Hormonal] among Egyptian Farmers. Journal of Applied Sciences Research, 9(7): 4404-4409.

Armah, F.A. (2011): Assessment of pesticide residues in vegetables at the farm gate: cabbage (Brassica oleracea) cultivation in Cape Coast, Ghana. Research Journal of Environmental Toxicology, 5(3): 180.

Baker BP, Benbrook CM, Groth E, and Lutz Benbrook K. (2002): Pesticide residues in conventional, integrated pest management (IPM)grown and organic foods: insights from three US data sets. Food Addit Contam; 19:427-446

Blanco-Munoz J, Mayanin-Morales M and Lacasana M. (2010): Exposure to organophosphate pesticides and male hormone profile in floriculturist of the state of Morelos, Mexico. Human Reproduction 25: 1787-1795.

Borut Poljšak and Rok Fink (2014): The Protective Role of Antioxidants in the Defence against ROS/RNS-Mediated Environmental Pollution. Oxidative Medicine and Cellular Longevity. Article ID 671539, 22 pages. 
Carpy, S.A.; Kobe, W. and Doe, J. (2000): Health risk low dose pesticides mixtures: A review of the 1985-1998 literature on combination toxicology and health risk assessment. J. Toxicol. Environ. Health. 3:1-25.

Diamanti-Kandarakis E, Bourguignon JP, Giudice LC, Hauser R, Prins GS, Soto AM, Zoeller RT and Gore AC (2009): "Endocrine-disrupting chemicals: an Endocrine Society scientific statement". Endocr. Rev. 30 (4): 293-342.

Dogheim SM1, Gad Alla SA, el-Syes SM, Almaz MM and Salama EY (1996): Organochlorine and organophosphorus pesticide residues in food from Egyptian local markets. J AOAC Int. 79(4):949-52.

Ecobichon DJ and Klaassen CD. (2001): Toxic effects of pesticides, Casarett \& Doull's. Toxicology: The Basic Science of Poisons, 6th ednNew York, USAMcGraw-Hill (p. 763-810).

Eskenazi B1, Bradman A and Castorina R. (1999): Exposures of children to organophosphate pesticides and their potential adverse health effects. Environ Health Perspect. Jun; 107 Suppl 3:409-19.

Gad Alla SA., Almaz M M , Thabet W M. and. Nabil M M (2015): Evaluation of Pesticide Residues in some Egyptian Fruits International Journal of Environment , 04 : 87-97.

Giwercman A1, Rylander L, and Lundberg Giwercman Y (2007): Influence of endocrine disruptors on human male fertility. Reprod Biomed Online. 15(6):633-42.

Haque QS, Jamal F and Rastogi SK (2012): Effect of organo-phosphorus on biochemical parameters on agricultural workers. Asian Journal of Biochemistry 7: 37-45.

Ilboudoa, S., Fouchea, E., Rizzatia, V., Toéb, A.M., Gamet-Payrastrea, L.and Guissoub, P.I. (2014): In vitro impact of five pesticides alone or in combination on human intestinal cell line Caco-2. Toxicol. Rep. 1: 474-489

Jelliffe, D.B., Jelliffe, E.F., Zerfas, A. and Neumann, C.G., (1989): Community nutritional assessment with special reference to less technically developed countries. 
Jensen TK, Giwercman A, Carlsen E, Scheike T and Skakkebaek NE. (1996): Semen quality among members of organic food associations in Zealand, Denmark. Lancet; 347:1844.

Jors E,; Morant, R.E.; Aguilar, G. C.; Huici, L. F.; Baelum J and Konradsen, F.( 2006): Occupational pesticides intoxications among farmers in Bolivia a cross-sectional study. Environ. Health. Global Sci, 5: 10.

Kamath V and Rajini PS (2007): Altered glucose homeostasis and oxidativeimpairment in pancreas of rats subjected to dimethoate intoxication.Toxicol. 231: 137-146.

Kamijima, M., H. Hibi, M. Gotoh, K. Taki, I. Saito, H. Wang, S. Itohara, T. Yamada, G. Ichihara, E. Shibata, T. Nakajima and Y. Takeuchi (2004): A survey of semen indices in insecticide sprayers. J. Occup. Health, 46: 109-118.

Lewwalter, J. and Leng, G. (1999): Consideration of individual susceptibility in adverse pesticide effects. Toxicol. Lett, 107:131-44.

Li X, Gao Y, Wang J, Ji G, Lu Y, Yang D, Shen H, Dong Q, Pan L, Xiao H and Baoli hu B (2016): Exposure to environmental endocrine disruptors and human health. Public Health Emerg 1:47.

Lu C, Barr D.B., Pearson M.A. and Waller L.A (2008): Dietary intake and its contribution to longitudinal organophosphorus pesticide exposure in urban/suburban children .Environ Health Perspect. 116 (4): $537-542$

Lu C, Toepel K, Irish R, Fenske RA, Barr DB and Bravo R. (2006): Organic diets significantly lower children's dietary exposure to organophosphorus pesticides. Environ Health Perspect; 114:260263.

Makelarski JA, Romitti PA, Rocheleau CM , Burns TL Stewart PA, Waters MA, Lawson CC, Bell EM, Lin S, Shaw GM, Olney RS and the National Birth Defects Prevention Study (2014): Maternal periconceptional occupational pesticide exposure and neural tube defects. Birth Defects Res A Clin Mol Teratol 100:877-886. 
Meeker JD. (2012): Exposure to environmental endocrine disruptors and child development. Arch Pediatr Adolesc Med.; 166(10):952-958.

Meeker JD, Ravi SR, Barr DB, and Hauser R (2008): Circulating estradiol in men is inversely related to urinary metabolites of nonpersistent insecticides. Reprod Toxicol. 25(2):184-91.

Meeker JD, Ryan L, Barr DB and Hauser R. (2006): Exposure to nonpersistent insecticides and male reproductive hormones. Epidemiology. 17(1):61-8.

NHLBI Obesity Education Initiative (2000): The practical guide: Identification, evaluation and treatment of overweight and obesity in adults. National Institutes of Health (98-4084).

Omoike OE, Lewis RC and Meeker JD (2015): Association between urinary biomarkers of exposure to organophosphate insecticides and serum reproductive hormones in men from NHANES 1999-2002. Reprod Toxicol.; 53:99-104.

Pflieger-Bruss S1, Schuppe HC and Schill WB. ( 2004): The male reproductive system and its susceptibility to endocrine disrupting chemicals. Andrologia.; 36(6):337-45.

Poljšak, B. and Fink, R. (2014): The protective role of antioxidants in the defence against ROS/RNS-mediated environmental pollution oxidative medicine and cellular longevity. 10.1155/2014/671539.

Salvi, R.M.; Lara, D.R.; Ghisolfi, E.S.; Portela, L.V.; Dias, R.D. and Souza, D.O. (2003): Neuropsychiatric evaluation in subjects chronically exposed to organophosphate pesticides. Toxicol. Sc., 72: 267-71.

Sarkar R, Mohankumar K and Chowdhury M. (2000): Effects of an organophosphate pesticide, quinalphos, on the hypothalamopituitary-gonadal axis in adult male rats, J Reprod Fertil, 118: 2938

Singh, S. and Sharma, N. (2000): Neurological syndromes following organophosphate poisoning. Neurol. India., 48: 308-13. 
Soliman, S.S., Abdel-Shafy A.A., and Zakaria M.E.( 2008): Erectile dysfunction in workers chronically- exposed to pesticides and organic solvents in Damietta Governorate Mansoura J. Forensic Med. Clin. Toxicology, 16(2):63-75.

Straube E, Straube W, Krüger E, Bradatsch M, Jacob-Meisel M and Rose HJ. (1999): Disruption of male sex hormones with regard to pesticides: pathophysiological and regulatory aspects, Toxicol Lett, vol. $107: 225-231$.

Tietz N W 1986: Textbook of clinical chemistry: Edited by Tietz N W Pp 1919. W B Saunders, Philadelphia. ISBN 0-7216-8886-1

WHO (1995): Physical status: the use and interpretation of anthropometry. Report of a WHO Expert Committee. WHO Technical Report Series 854. Geneva: World Health Organization.

WHO (2008): Waist circumference and waist-hip ratio: report of a WHO expert consultation, Geneva, 8-11. ISBN 9789241501491

WHO (World Health Organization)/UNEP (United Nations Environment Programme)( 2013): The State-of-the-Science of Endocrine Disrupting Chemicals - 2012 (Bergman Å, Heindel JJ, Jobling S, Kidd KA, Zoeller RT, eds .

Zheng Xie, Haijiang Lin, Renfei Fang, Weiwei Shen, Shuguang Li, and Bo Chen (2015): "Effects of a fruit-vegetable dietary pattern on oxidative stress and genetic damage in coke oven workers: a cross-sectional study," Environmental Health, 14: 40.

Zoeller RT. Brown T. R, Doan L. L., Gore A. C., Skakkebaek N. E., Soto A. M., Woodruff T. J. and Vom Saal F. S.(2012): EndocrineDisrupting Chemicals and Public Health Protection: A Statement of Principles from The Endocrine Society. Endocrinology , 153(9):4037-110. 


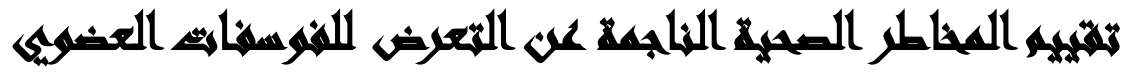 هيs اللرجال}

$[r]$

محمود سري البخاري(')- أسامة محمد رضوان(') - هالة إبراهيم عوض اللهان(')

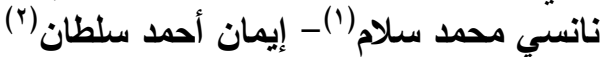

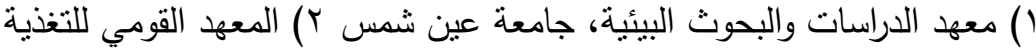

\section{المستخليص}

على مدى العشرين سنه الماضية أولى العلماء قدرا كبيرا من الاهتمام لتأثنر المواد المسببة

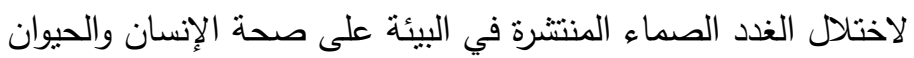

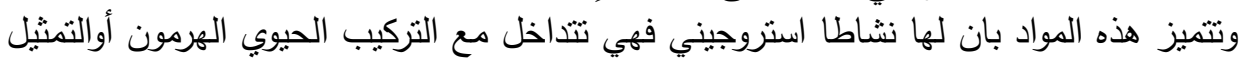

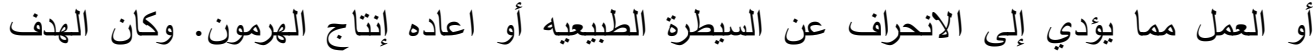

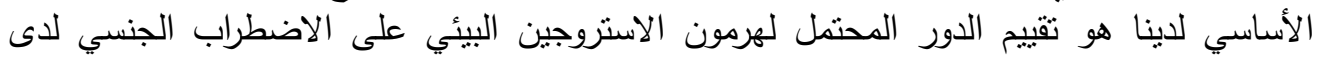

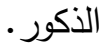
الطريقة: دراسة مستعرضة استهوفت بr من الذكور الأصحاء وقداستطلعنا خصائص نمط الحياة،

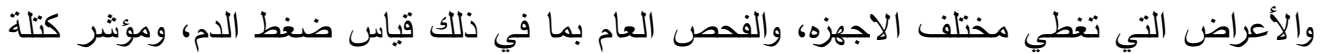

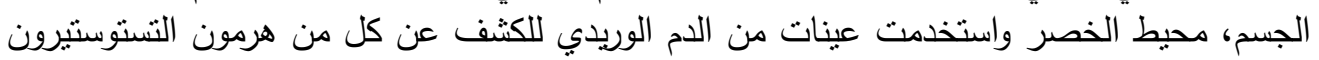

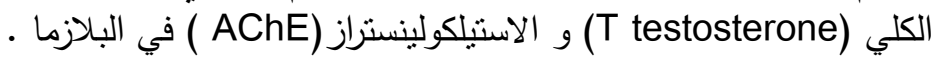

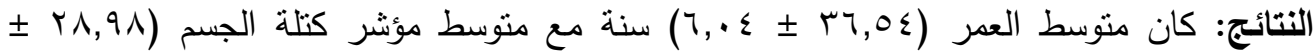

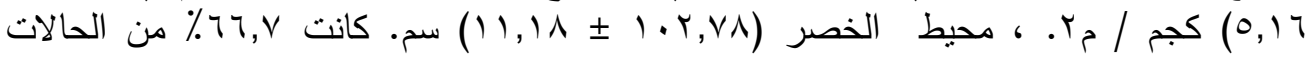

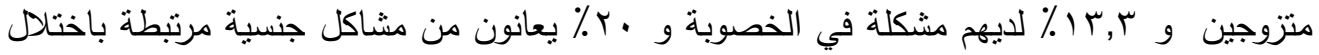

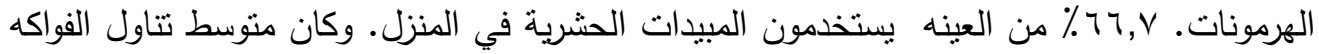

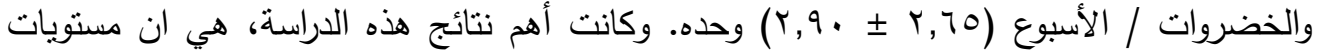

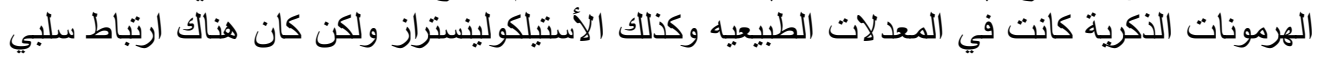

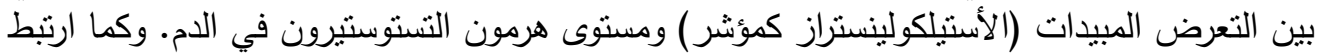

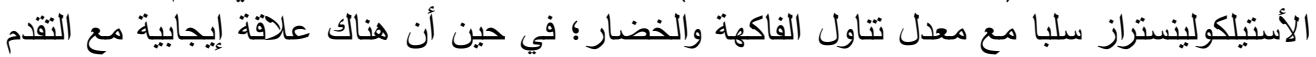

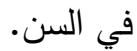
الكلمات الدالة: الفوسفات العضوي، إلاستيروجينات الصناعية، أستيلكولينستراز ، الهرمونات الذكريه،

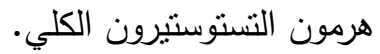

